\title{
Delamination prediction in orthogonal machining of carbon long fiber-reinforced polymer composites
}

\author{
C Santiuste', A Olmedo', X Soldani ${ }^{2}$ and H Miguélez ${ }^{2}$
}

\begin{abstract}
Machining processes of composites are common operations in industry involving elevated risk of damage generation in the workpiece. Long fiber reinforced polymer composites used in high-responsibility applications require safety machining operations guaranteeing workpiece integrity. Modeling techniques would help in the improvement of machining processes definition; however, they are still poorly developed for composites. The aim of this paper is advancing in the prediction of damage mechanisms involved during cutting, including out-of-plane failure causing delamination. Only few works have focused on three-dimensional simulation of cutting; however, this approach is required for accurate reproduction of the complex geometries of tool and workpiece during cutting processes. On the other hand, cohesive interactions have proved its ability to simulate out-of-plane failure of composites under dynamic loads, as impact events. However, this interlaminar interaction has not been used up to date to model out-of-plane failure induced during chip removal. In this paper, both a classical damage model and cohesive interactions are implemented in a three-dimensional model based on finite elements, in order to analyze intralaminar and interlaminar damage generation in the simplified case of orthogonal cutting of carbon LFRP composite. More realistic damage predictions using cohesive interactions were observed. The strong influence of the stacking sequence on interlaminar damage has been demonstrated.
\end{abstract}

\section{Keywords}

Cutting carbon LFRP composite, damage prediction, delamination, cohesive interaction

\section{Introduction}

Machining processes are commonly required to achieve final dimensional and assembly specifications in carbon long fiber reinforced polymer (LFRP) composite components. ${ }^{1}$ The most frequent defects involved in composite cutting are delamination, fiber pull-out, interlaminar cracks and thermal degradation. Machining-induced damage has significant importance in industry: for instance, poor hole quality in composite drilling accounts for an estimated $60 \%$ of all part rejection. ${ }^{2}$ Surface integrity of the workpiece is critical for the subsequent assembly stage and, of course, during service life of the component. ${ }^{3}$

Measurement of damage is costly, time consuming and sometimes needs destructive techniques to analyze the component. Despite the importance of prediction of damage mechanisms induced during machining; only few works in scientific literature deal with modeling of cutting processes in composite. These works are mostly focused on two-dimensional (2D) approaches to orthogonal cutting. 2D modeling presents the advantage of reduced computational cost; however, it is neither possible to reproduce out-of-plane failure mechanisms nor simulating quasi-isotropic laminates commonly used in structural applications. Some examples of 2D finite element analysis can be found in References [4 and 5]. Ramesh et $\mathrm{al.}^{4}$ analyzed the

\footnotetext{
'Department of Continuum Media and Structural Analysis, Universidad Carlos III de Madrid, Madrid, Spain

${ }^{2}$ Department of Mechanical Engineering, Universidad Carlos III de Madrid, Madrid, Spain

\section{Corresponding author:}

H Miguélez, Department of Mechanical Engineering, Universidad Carlos III de Madrid, Avda. Universidad 30, 289II, Leganés, Madrid, Spain Email: mhmiguel@ing.uc3m.es
} 
influence of orientation for different types of LFRPs. Failure mechanism based on fiber-matrix cracking was implemented, obtaining that the load needed to induce failure was dependent on the fiber orientation. Mahdi and Zhang ${ }^{5}$ carried out a 2D analysis reproducing an equivalent homogeneous material predicting cutting forces of LFRP composite depending on the fiber orientation. A new approach of 2D modeling of orthogonal cutting of carbon LFRP using discrete element method (DEM) has been presented in Reference [6]. The observation of the chip formation using a high-speed video camera made possible to validate qualitatively the results of numerical simulation by discrete elements. Although 2D approaches have given interesting information about composite cutting, it is not possible to simulate important phenomena such as out-of-plane failure. Some other advances in the knowledge of orthogonal cutting of composites have been achieved using 2D approaches. For instance, the authors have showed in previous works the influence of material properties and numerical parameters on the mechanisms of chip generation and subsurface damage in the machined surface References [7 and 8]. The validity of the hypothesis assumed in 2D approaches to LFRP composite cutting has been analyzed in Reference [9]. Out-of-plane failure in orthogonal cutting of composite was analyzed using a 3D model based on finite elements. The influence of stacking sequence on the generation of damage using Hou criteria was demonstrated.

Concerning the simulation of the complete process of chip removal in the case of real industrial machining processes of composites, mostly drilling and milling of the contour involving complex tool geometries and oblique cutting, only simplified modeling tools have been developed up to date.

Modeling of drilling processes involves elevated difficulty, because of the need of simulate drill rotation and feed using both damage and erosion criteria at the elements leading to high computational cost. It is commonly assumed in the literature that the drill acts like a punch that pierces through the laminate. ${ }^{10,11}$ This is the approach used by Durao et al. ${ }^{12}$ and Singh et al. ${ }^{13}$ when studying glass fiber reinforced polymer composites (GFRPs) drilling; they showed the influence of the drill point angle in the induced damage. Also, analytical efforts have been done with the objective of relating delamination with the applied trust force ${ }^{14}$ that seems to be one of the most influencing factors in the generation of out-of-plane failure during drilling. ${ }^{15}$

Concerning milling processes, few predictive tools can be found in the literature, even in the simplified case of orthogonal cutting which could be considered a preliminary approach to the complex milling process involving interrupted cutting and variable chip thickness. ${ }^{16}$
As it was commented previously, delamination is one of the undesired effects of machining using non-appropriate cutting parameters or worn tool. Different authors have focused attention on the experimental analysis of machining induced delamination.

Davim et al. ${ }^{17}$ investigated the influence of cutting parameters and the matrix on the specific cutting force, delamination factor and surface roughness. The feed was the most influencing parameter on delamination factor.

Abrao et al. ${ }^{18}$ checked the influence of tool geometry and cutting parameters on delamination during drilling of glass FRP. It was shown the strong influence of the drill geometry in competition with the thrust force, commonly assumed to be the most influencing factor. In this work, it was demonstrated that the drill responsible for the highest thrust force caused the second smallest delaminated area.

A novel technique for measurement of delamination factor after drilling FRP laminates, using digital analysis, was presented in Reference [19]. The experimental results indicated that the use of digital analysis is suitable for control of drilling-induced damage in carbon fiber reinforced plastics.

The same authors successfully applied this technique for damage control in high speed drilling of glass FRP. ${ }^{20}$ Delamination decreases as the cutting speed is increased within the cutting range tested, probably due to increased cutting temperature with spindle speed, leading to enhanced softening of the matrix and less delamination.

Krishnaraj et al. ${ }^{21}$ explored high speed drilling of carbon FRP and demonstrated the greater influence of feed rate on thrust force, push-out delamination and diameter of the hole. Lower feed rates reduce thrust force and push-out delamination, while higher feed rates lead to hole diameter closer to the nominal value. Spindle speed is one of the major determinants of the circularity of the drilled hole. On the other hand, spindle speed and feed rate had negligible influence on peel-up delamination, within the tested range.

In a recent review dealing with drilling of composites $^{22}$ the authors summarize main contributions in the literature concerning drilling-induced delamination (mainly experimental and analytical approaches), highlighting the importance of this phenomenon and showing some techniques, tools and operations developed to minimize the occurrence of delamination.

Studies of milling carbon fiber reinforced polymer composites (CFRPs) are somewhat limited compared to drilling. Hintze et al. ${ }^{23}$ focused on milling CFRPs experiments and observed that occurrence of delamination is closely related to tool wear and also with top layer fiber cutting angle. Lopez de Lacalle et al. ${ }^{24}$ studied the performance of multi-tooth cutting tools 
during the trimming process of CFRPs. The authors demonstrated the superior performance of multi-tooth cutting tools with TiAlN coating in comparison to the behavior of straight edge polycrystalline diamond (PCD) tools for finishing operations. Davim and Reis $^{25}$ established a model using multiple regression analysis between cutting velocity and feed rate with the surface roughness and damage in a CFRPs composite material. Feed rate was most influencing parameter on both surface roughness and delamination factor. Similar behavior concerning the influence of feed rate on workpiece integrity indicators was observed by Davim et al. $^{26}$ during milling of glass FRP. Karpat et al. ${ }^{27}$ developed a mechanistic cutting force model for milling CFRPs based on experimentally collected cutting force data during slot milling of unidirectional CFRPs laminates using two different polycrystalline diamond cutters. No delamination at the sides of the slot for fiber angle equal to $45^{\circ}$ was observed.

Delamination damage occurs not only in composite cutting but also in other dynamic processes such as impact loading; see for instance Reference [28]. It is accepted in the scientific community that the prediction of delamination requires the use of cohesive interactions modeling the interface between plies. ${ }^{29}$ This type of interaction has been successfully applied in the modeling of dynamic loading of composites, see for instance Reference [30], and also in the simplified models of drilling assuming the process to be similar to punching. ${ }^{12}$ The lack of works developing 3D modeling (required to reproduce composite machining in industry) is reported in a recent review. ${ }^{31}$ Thus, cohesive interactions owing to ability to simulate out-of-plane failure in dynamic loading of composites have not been used up to date to model out-of-plane failure induced during cutting in complete simulations including chip removal.

The aim of this work is highlighting the mechanisms of machining-induced damage in carbon LFRP composite, using numerical modeling based on finite elements. The work focuses on orthogonal cutting of laminates introducing cohesive interactions at the interface between plies and comparing with the classical model of Hou for out-of-plane failure prediction. Great differences between both approaches and some interesting results concerning the influence of stacking sequence in resultant damage have been found.

\section{Numerical model}

The scheme of the numerical model developed using the commercial Finite Element code ABAQUS/Explicit is presented in Figure 1(a) (boundary conditions and geometry) and (b) (detail of the interface tool/chip). The bottom face boundary conditions represent the clamping used in the experiments, while the restricted longitudinal displacements $\left(U_{\mathrm{x}}=0\right)$ denote that the model represents a portion of the composite plate. The element size should be defined under the point of view of both accuracy and time efficiency of the calculation, because of the dependence of time step on element size. This time is in the order of that required by a dilatational wave to cross the smallest element, leading to large calculation time. Dynamic explicit analysis was carried out including geometric non-linearity and large deformations options. The tool was meshed with 8-node brick elements with reduced integration $(\mathrm{C} 3 \mathrm{D} 8 \mathrm{R}$ in ABAQUS/Explicit notation) and wedge elements (C3D6 in ABQUS/Explicit notation) were used for the laminate. ${ }^{32}$ The use of wedge elements (prismatic element with triangular section) minimizes the dependence of the results with mesh orientation in the ply plane. Despite the computational cost (around 72 hours), mass scaling was not included because it can distort the dynamic behavior of the model.

A mesh sensibility analysis with element size was carried out for the deformable workpiece. Two different meshes were checked. First mesh was based on wedge element size equal to 7 microns (around the interface tool/chip), using 121,056 elements for the workpiece and 2776 brick elements for the tool. Second mesh was based on wedge element size equal to 5 microns (around the interface), using 148,448 elements for the workpiece and 2776 brick elements for the tool. No significant differences were observed between both meshes when predicting cutting forces or damage; however, the computational cost was significantly increased (around 25\%) when the element size was decreased. Thus, element size around the cutting zone was $7 \mathrm{~mm}$, and reasonably accuracy and computational cost were achieved with the model.

The tool was assumed to behave rigid. The interaction between workpiece and tool was modeled using the algorithm surface-node surface contact available in ABAQUS/Explicit. Due to the deletion of elements during cutting process, the contact was defined between the tool surface and all the composite plate nodes in the region adjacent to the contact area. In addition, a selfcontact condition was used to prevent penetration between eroded composite elements. A constant coefficient of friction equal to 0.5 at the tool/workpiece interface was assumed. ${ }^{7}$ In order to validate the numerical model, machining parameters are identical to those used in the experiments reported in References [ 6 and 33]. Clearance and rake angles were $6^{\circ}$ and $5^{\circ}$, respectively, cutting speed was $6 \mathrm{~m} / \mathrm{min}$ and nose radius was $0.05 \mathrm{~mm}$.

The anisotropic composite was modeled with an elastic behavior up to failure. Failure was represented with Hou model ${ }^{34}$ presented in Table 1. Hou criteria 


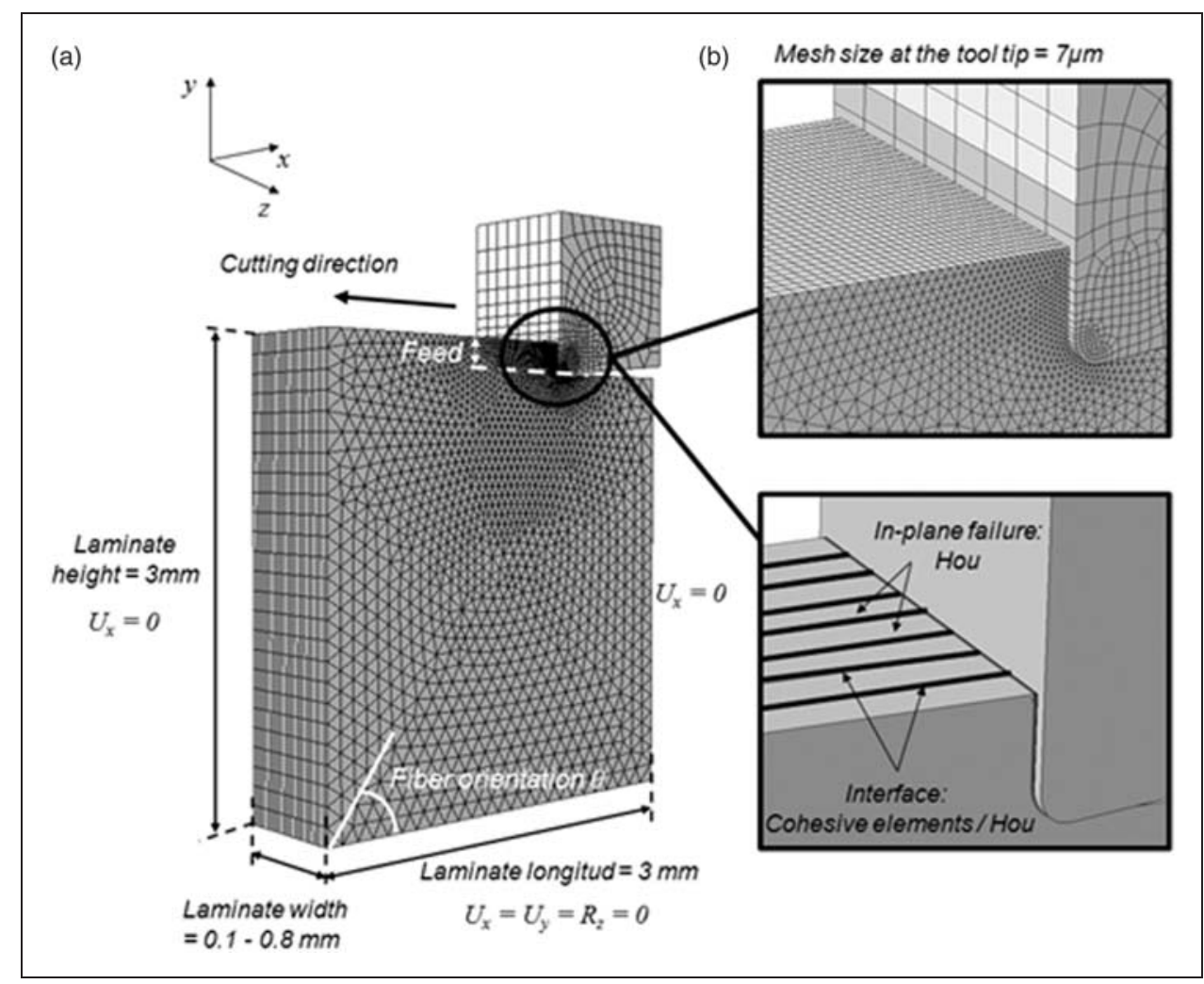

Figure I. Scheme of numerical model (a) geometry and boundary conditions; (b) detail of interface modeling.

Table I. Hou damage criteria

\begin{tabular}{ll}
\hline Failure mode & Hou formulation \\
\hline Fiber tension & $d_{\mathrm{ft}}^{2}=\left(\frac{\sigma_{11}}{X_{\mathrm{T}}}\right)^{2}+\left(\frac{\sigma_{12}^{2}+\sigma_{13}^{2}}{S_{\mathrm{L}}^{2}}\right)$ \\
Fiber compression & $d_{\mathrm{fc}}^{2}=\left(\frac{\sigma_{11}}{X_{\mathrm{C}}}\right)^{2}+\left(\frac{\sigma_{12}^{2}+\sigma_{13}^{2}}{S_{\mathrm{L}}^{2}}\right)$ \\
Matrix cracking & $d_{\mathrm{mt}}^{2}=\left(\frac{\sigma_{22}}{Y_{\mathrm{T}}}\right)^{2}+\left(\frac{\sigma_{12}}{S_{\mathrm{L}}}\right)^{2}+\left(\frac{\sigma_{23}}{S_{\mathrm{T}}}\right)^{2}$ \\
Matrix crushing & $d_{\mathrm{mc}}^{2}=\frac{\mathrm{I}}{4}\left(\frac{\sigma_{22}}{S_{\mathrm{T}}}\right)^{2}+\left(\frac{Y_{\mathrm{c}} \sigma_{22}}{4 S_{\mathrm{T}}^{2}}\right) \frac{\sigma_{22}}{Y_{\mathrm{C}}}+\left(\frac{\sigma_{12}}{S_{\mathrm{L}}}\right)^{2}$ \\
Delamination & $d_{\mathrm{del}}^{2}=\left(\frac{\sigma_{33}}{Z_{\mathrm{T}}}\right)^{2}+\left(\frac{\sigma_{23}}{S_{\mathrm{T}}}\right)^{2}+\left(\frac{\sigma_{13}}{S_{\mathrm{L}}}\right)^{2}$
\end{tabular}

are based on Chang-Chang failure criteria including out-of-plane stresses. ${ }^{35}$ Hou proposed for fiber failure criterion the same formulation under tensile and compressive loading, including longitudinal shear stresses $\sigma_{12}$ and $\sigma_{13}$. In matrix cracking criterion, Hou included the transverse shear stress $\sigma_{23}$. Hou also introduced a delamination criterion for tensile out-of-plane stresses $\left(\sigma_{33}>0\right)$. Parameters in Table 1 are the following: $\sigma_{11}$, $\sigma_{22}$ and $\sigma_{33}$ are the stresses in longitudinal, transverse and through-the-thickness direction respectively; $\sigma_{12}$, $\sigma_{23}$ and $\sigma_{13}$ are the shear stresses; $X_{\mathrm{T}}$ and $X_{\mathrm{C}}$ are the tensile and compressive strengths in longitudinal direction; $Y_{\mathrm{T}}$ and $Y_{\mathrm{C}}$ are the tensile and compressive strengths in the transverse direction; $Z_{\mathrm{T}}$ is the tensile strength through-thickness direction; $S_{\mathrm{L}}$ is the longitudinal shear strength and $S_{\mathrm{T}}$ is the transverse shear strength (failure occurs when $d_{\mathrm{ij}}$ reaches the value 1 ).

Hou formulation was implemented for the 3D analysis through a VUMAT subroutine, developed to model the long fiber composite behavior, including a procedure to degrade material properties. Under a given load, the stresses at each integration point were computed in the user subroutine. Then, each failure criteria was computed as a function of stresses and, if any failure occurs, the material properties at that point were degraded according to the mode of failure. When the failure criterion was reached, the stresses at the damaged area were reduced to reproduce the properties degradation. The updated stresses depend on the failure mode: fiber failure produces the complete collapse of the material at that point 


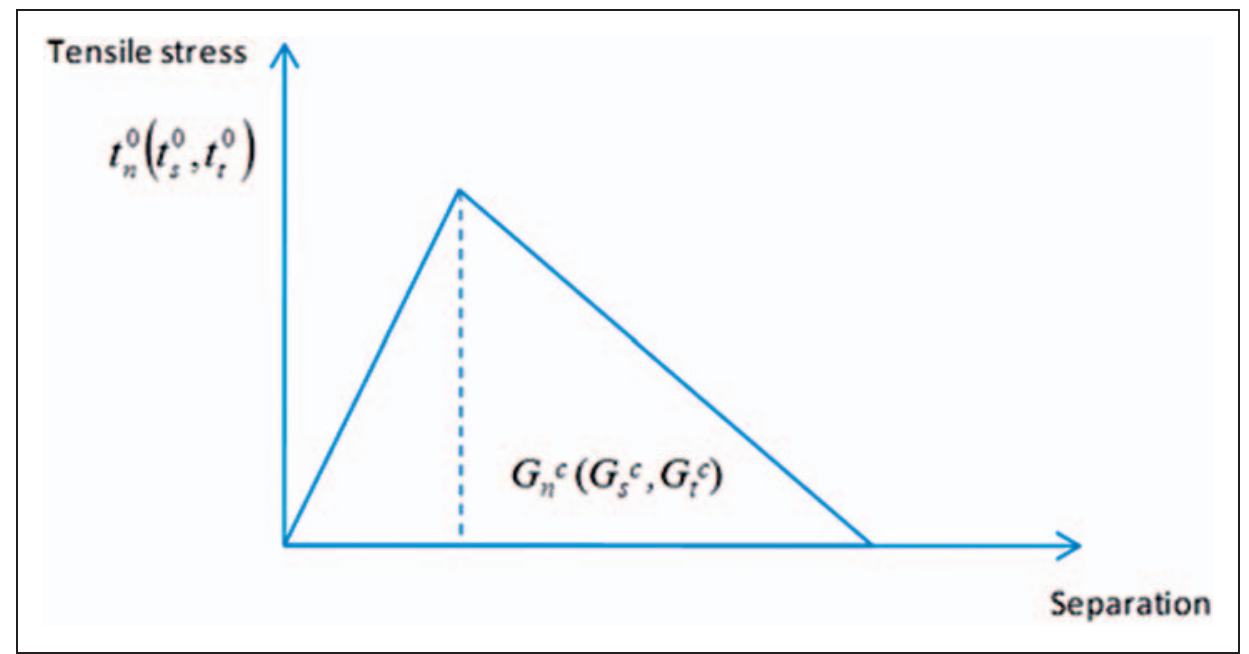

Figure 2. Traction separation response for cohesive interactions: tensile stress vs separation.

$\left(\sigma_{11}=\sigma_{22}=\sigma_{33}=\sigma_{12}=\sigma_{23}=\sigma_{13}=0\right)$, whereas delamination just avoids supporting stresses in the normal direction $\left(\sigma_{33}=\sigma_{23}=\sigma_{13}=0\right)$.

Elastic properties reduction could lead to distorted elements involving numerical problems, thus the model requires the use of an element erosion criterion. The stresses on a damaged element drop to values close to zero while large deformations appear. These elements do not contribute to the strength or the stiffness of the plate, but they can cause lack of convergence during simulation and instability problems. Erosion criterion, based on maximum strain criteria, was implemented in the VUMAT subroutine to remove the distorted elements. After each time increment, the longitudinal strains $\left(\varepsilon_{11}, \varepsilon_{22}\right.$ and $\left.\varepsilon_{33}\right)$ were evaluated, and the element was removed if one of the strains reached a critical value. The strains used in the erosion criterion were $\varepsilon_{11}^{\max }=0.3$, $\varepsilon_{22}^{\max }=0.5$ and $\varepsilon_{33}^{\max }=0.5$, high enough to prevent the deletion of elements that contribute to the strength of the plate. Thus, numerical problems are avoided and at the same time only strongly damaged elements are deleted. These values were established from the authors expertise in comparable applications. ${ }^{36}$ Since element deletion is controlled by the subroutine formulation distortion control was not used.

A modification of the model was done, using cohesive interactions between plies for simulating delamination. Modeling delamination by cohesive interaction allows reproducing delamination propagation as a fracture mechanics phenomenon, instead of stresses-based models as it is the case of Hou criteria. The surfacebased cohesive interaction available in ABAQUS was used to predict delaminated area. Figure 2 shows typical traction-separation response using cohesive interaction, ${ }^{37}$ a linear elastic behavior is considered until delamination onset is verified. Thus, a failure criterion
Table 2. Material properties including matrix cohesive characteristics

\begin{tabular}{ll}
\hline Carbon epoxy T300/9I4 & \\
\hline Longitudinal modulus, $E_{\mathrm{I}}(\mathrm{GPa})$ & 136.6 \\
Transverse modulus, $E_{2}(\mathrm{GPa})$ & 9.6 \\
In plane shear modulus, $G_{12}(\mathrm{GPa})$ & 5.2 \\
Major Poisson's ratio, $v_{12}$ & 0.29 \\
Through thickness Poisson's ratio, $v_{23}$ & 0.4 \\
Longitudinal tensile strength, $X_{\mathrm{T}}(\mathrm{MPa})$ & 1500 \\
Longitudinal compressive strength, $X_{\mathrm{c}}(\mathrm{MPa})$ & 900 \\
Transverse tensile strength, $Y_{\mathrm{T}}(\mathrm{MPa})$ & 27 \\
Transverse compressive strength, $Y_{\mathrm{c}}(\mathrm{MPa})$ & 200 \\
In plane shear strength, $S_{12}(\mathrm{MPa})$ & 80 \\
Longitudinal tensile strength, $Z_{\mathrm{T}}(\mathrm{MPa})$ & 27 \\
Longitudinal shear strength, $\mathrm{S}_{\mathrm{L}}(\mathrm{MPa})$ & 80 \\
Transverse shear strength, $\mathrm{S}_{\mathrm{T}}(\mathrm{MPa})$ & 60 \\
Maximum normal traction stress $t_{\mathrm{n}}^{0}(\mathrm{MPa})$ & 55 \\
Maximum shear traction stress $t_{\mathrm{s}}^{0}(\mathrm{MPa})$ & 68 \\
Maximum shear traction stress $t_{\mathrm{t}}^{0}(\mathrm{MPa})$ & 68 \\
Critical fracture energy in normal direction $G_{\mathrm{n}}^{\mathrm{C}}\left(\mathrm{kJ} / \mathrm{m}^{2}\right)$ & 0.3 \\
Critical fracture energy in shear direction $G_{\mathrm{S}}^{\mathrm{C}}\left(\mathrm{kJ} / \mathrm{m}^{2}\right)$ & 2.023 \\
Critical fracture energy in shear direction $G_{\mathrm{t}}^{\mathrm{C}}\left(\mathrm{kJ} / \mathrm{m}^{2}\right)$ & 2.023 \\
Matrix cohesive property parameter $\eta$ & 1.75 \\
\hline
\end{tabular}

is required to predict damage. In this work, delamination onset was predicted by a quadratic stress criterion considering out-of-plane stresses (equation (1)).

$$
\left\{\frac{t_{\mathrm{n}}}{t_{\mathrm{n}}^{0}}\right\}^{2}+\left\{\frac{t_{\mathrm{s}}}{t_{\mathrm{s}}^{0}}\right\}^{2}+\left\{\frac{t_{\mathrm{t}}}{t_{\mathrm{t}}^{0}}\right\}^{2}=1
$$




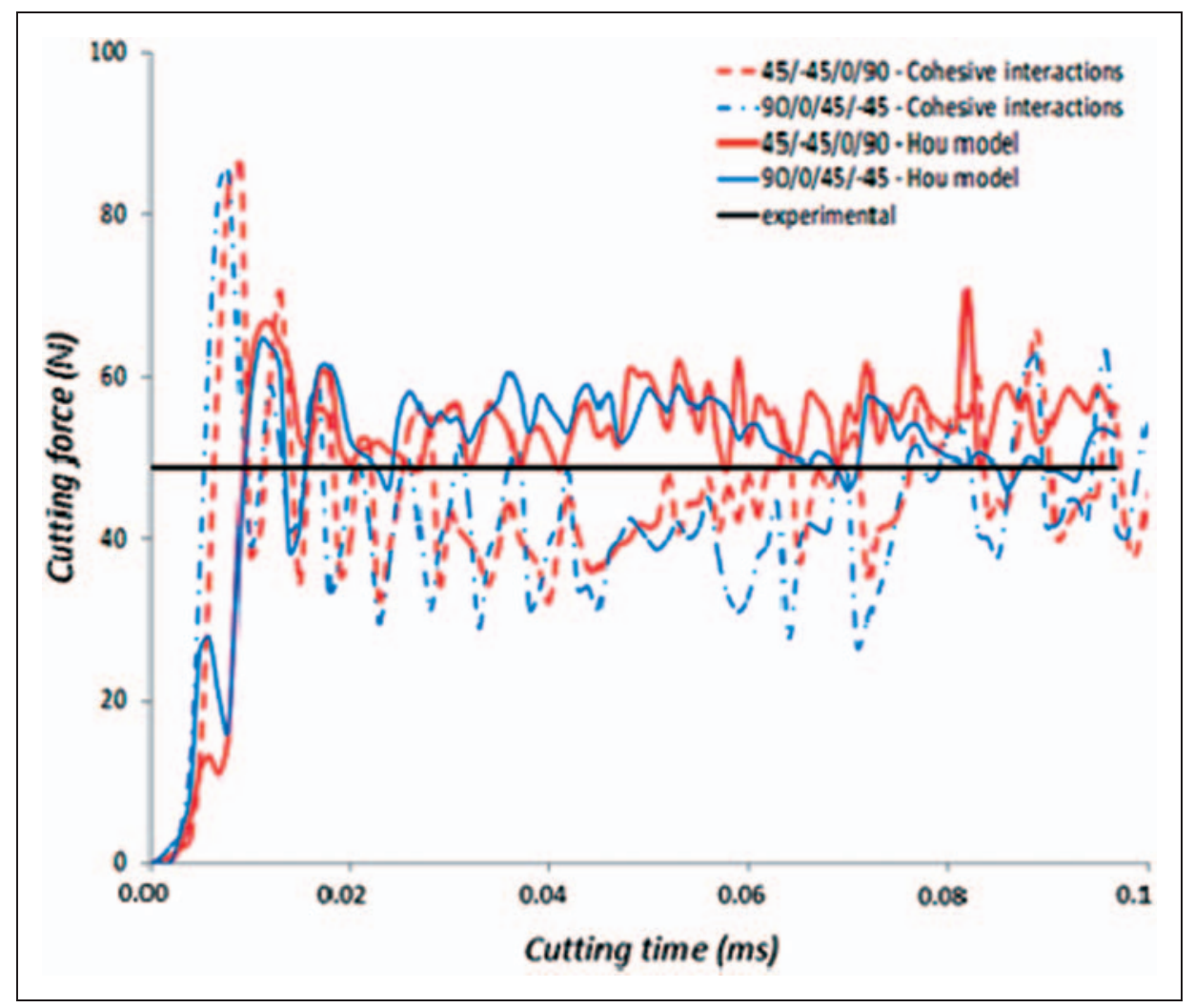

Figure 3. Predicted and experimental cutting forces.

where $t_{\mathrm{n}}$ is the normal traction stress, $t_{\mathrm{s}}$ and $t_{\mathrm{t}}$ are the shear traction stresses. $t_{\mathrm{n}}^{0}, t_{\mathrm{S}}^{0}$ and $t_{\mathrm{t}}^{0}$ are maximum admissible values of stresses.

Once damage is verified, ABAQUS cohesive interaction requires the definition of a damage evolution law. In this work, the behavior of the cohesive interaction after damage onset was defined by BenzeggaghKenane (BK) damage model. ${ }^{37}$ BK model is based on the energy dissipated due to failure considering a traction-separation response according to equation (2).

$$
G_{\mathrm{n}}^{\mathrm{C}}+\left(G_{\mathrm{s}}^{\mathrm{C}}+G_{\mathrm{n}}^{\mathrm{C}}\right)\left(\frac{G_{\mathrm{S}}}{G_{\mathrm{T}}}\right)^{\eta}=G^{\mathrm{C}}
$$

where $G_{\mathrm{S}}=G_{\mathrm{S}}+G_{\mathrm{t}}$ and $G_{\mathrm{T}}=G_{\mathrm{n}}+G_{\mathrm{S}}$. The variables $G_{\mathrm{n}}, G_{\mathrm{s}}$ and $G_{\mathrm{t}}$ refer to the work done by the traction and its conjugate relative displacement in the normal direction, the first and the second shear directions, respectively. The quantities $G_{\mathrm{n}}^{\mathrm{c}}, G_{\mathrm{s}}^{\mathrm{c}}$ and $G_{\mathrm{t}}^{\mathrm{c}}$ refer to the critical fracture energies required to cause failure in the normal, the first and the second shear directions, respectively. $\eta$ is a cohesive property parameter. BK model is especially useful when the critical fracture energies during deformation purely along the first and the second shear directions are the same; i.e., $G_{\mathrm{s}}^{\mathrm{c}}=G_{\mathrm{t}}^{\mathrm{c}}$.
The values implemented in the model were coherent and equivalent to those used for the Hou out-of-plane failure model. On the other hand, delamination model based on cohesive interactions have been used in a previous work dealing with dynamic loading of composite; numerical results included in the previous work matched reasonably experimental impact tests. ${ }^{38}$

A 3D model was applied to simulate orthogonal cutting of quasi-isotropic laminates considering two stacking sequences $[45 /-45 / 0 / 90] \mathrm{s}$ and $[90 / 0 / 45 /-45] \mathrm{s}$. The laminate thickness was stated equal to $0.8 \mathrm{~mm}$. The validity of the thickness selected is discussed in Reference [9].

The model was validated through the comparison with experimental results provided in recent works ${ }^{6,33}$ dealing with orthogonal cutting of the carbon-epoxy LFRP composite T300/914. The values of experimental cutting forces (in $\mathrm{N} / \mathrm{mm}$ ) are obtained as the ratio between the average level of the cutting forces and the laminate thickness. The large number of elements needed to simulate the laminate thickness used in the experiments complicates the simulation of real cutting. The results about forces are normalized referring to the force needed to cut a laminate $1-\mathrm{mm}$ thick, and resultant forces are given in $\mathrm{N} / \mathrm{mm}$. 


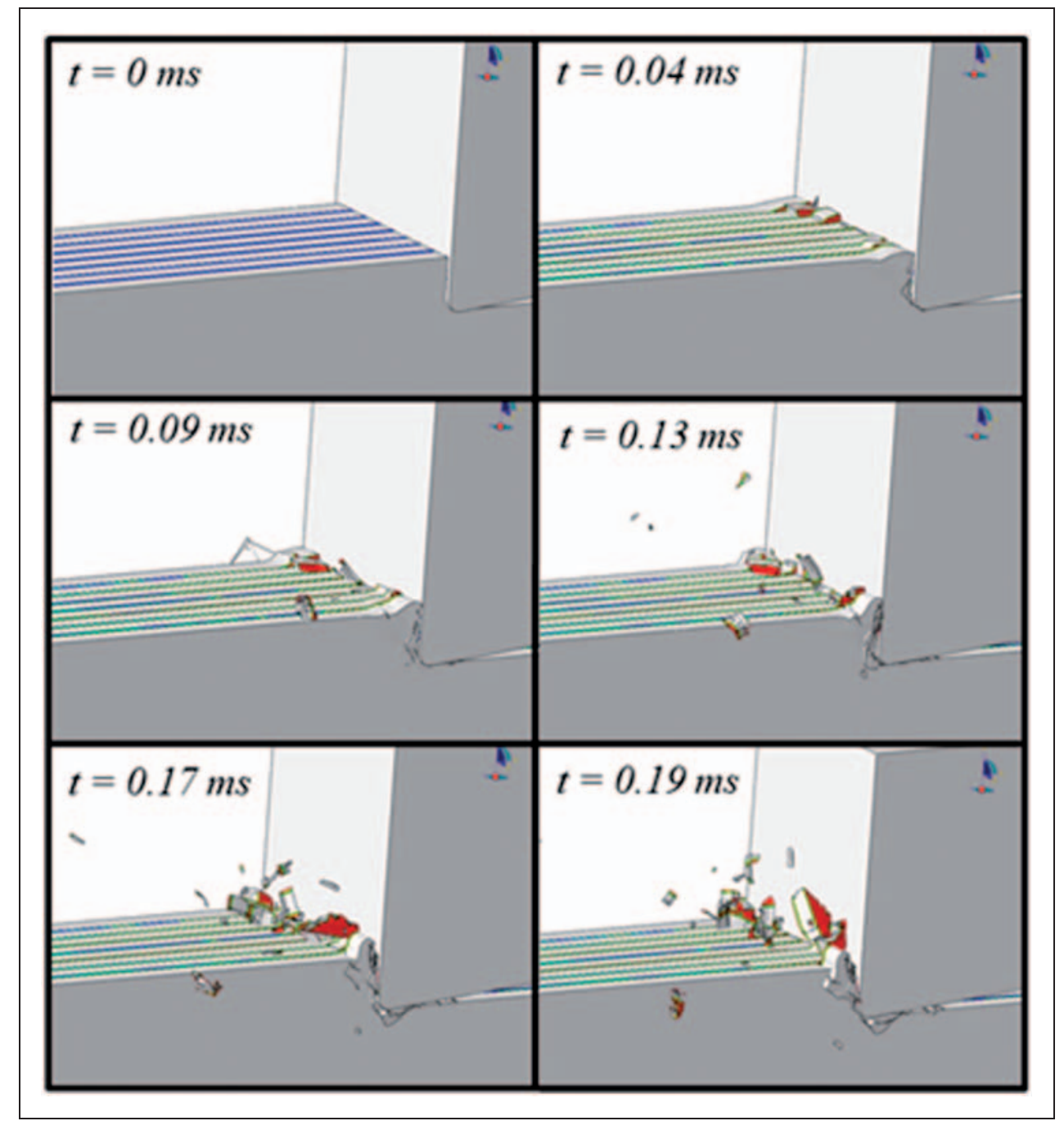

Figure 4. Evolution of chip generation with cutting time (stacking sequence $[45 / 45 / 0 / 90]_{S}$ ).

The thickness of the experimental laminate $(6.4 \mathrm{~mm})$ was obtained from the detailed work developed by Iliescu. ${ }^{33}$ The material properties used in the numerical models presented in this work are summarized in the Table 2.

Figure 3 shows experimental and predicted cutting forces for quasi-isotropic laminates, in both cases of delamination modeled with Hou criteria and cohesive interactions. Reasonable accuracy is observed, although cohesive interaction lead to slightly diminished cutting force, this behavior can be related to the increased trend to generate damage, as will be shown in the following sections.

\section{Results and discussion}

The evolution of chip formation during cutting is shown in Figure 4. Chip morphology is not uniform through the laminate thickness, since composite is non-homogeneous material. Each ply owing a given orientation of the fiber presents different evolution of chip and damage extension; the discontinuity between plies is one of the reasons causing delamination. Moreover, out-of-plane loads - neglected when plain stress state is assumed, that is the common hypothesis in $2 \mathrm{D}$ analysis - enhance delamination. Detailed analysis of the influence of fiber orientation on chip morphology and damage, performed with a $2 \mathrm{D}$ numerical model of LFRPs cutting can be found in previous work of the authors. ${ }^{7,8}$ In the case of unidirectional laminates using the 3D approach, the analysis of the influence of fiber orientation gives similar results to those obtained with the 2D model when the laminate is thin enough to ensure the validity of plane stress assumption, as has been explained in previous works of the authors. ${ }^{79}$ The model also predicted similar influence of fiber orientation in cutting forces as that obtained by other authors. ${ }^{33}$ On the other hand, no 


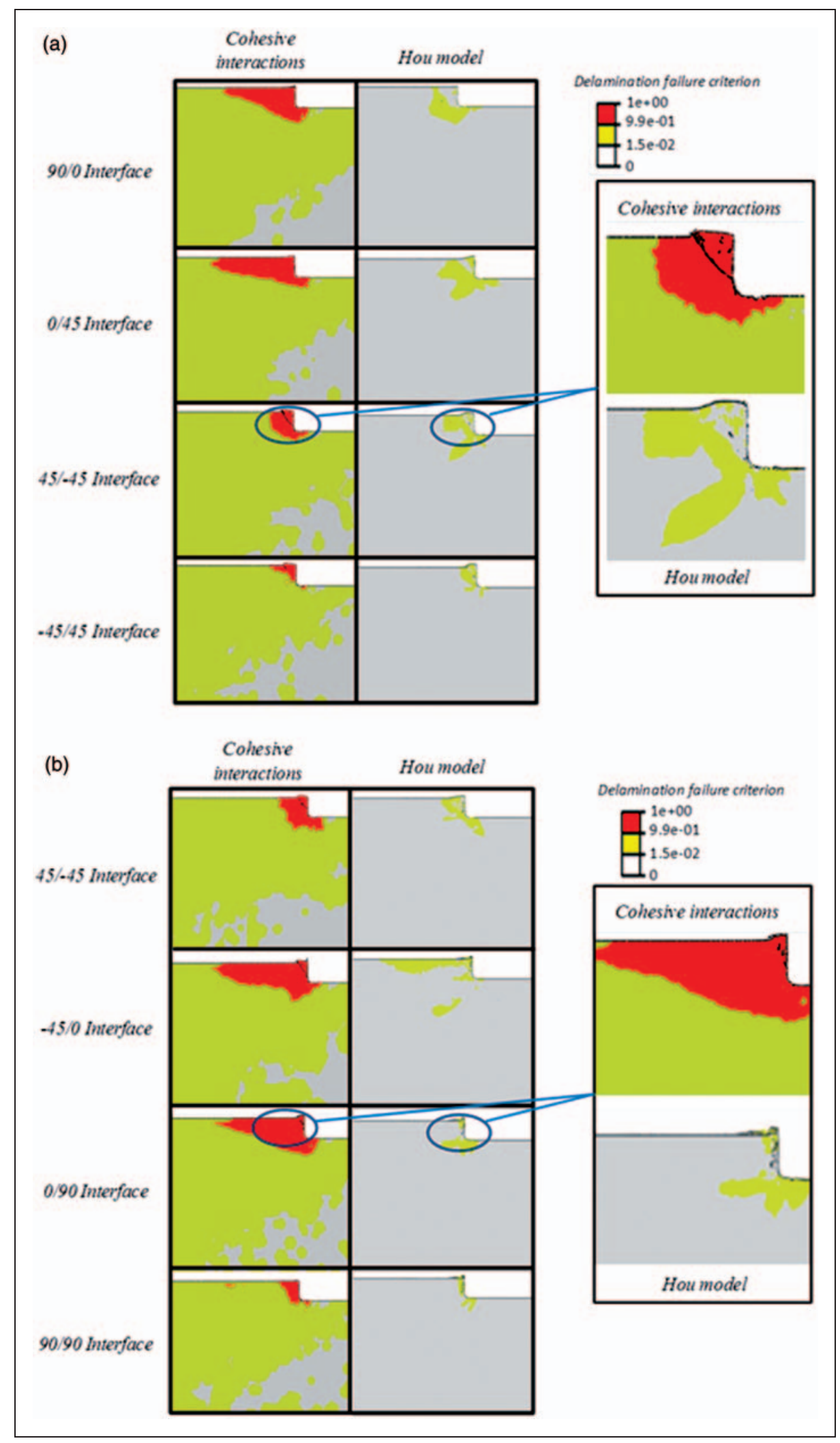

Figure 5. (a) Delamination predicted using cohesive interaction (left column) and Hou model (right column). Stacking sequence [90/ 0/45/ 45]s. (b) Delamination predicted using cohesive interaction (left column) and Hou model (right column). Stacking sequence [45/ $45 / 0 / 90]_{s}$. 
influence of the cohesive interaction was observed when modeling a unidirectional laminate. This result is coherent with the trend to develop delamination especially at the interface between plies with different orientation. Main interest of the 3D approach is the possibility of reproducing stacking sequence of the multidirectional laminate and thus the discussion is focused on these results. Because of the novelty of 3D modeling of cutting processes, ${ }^{31}$ it was not possible to compare the results presented in this paper with numerical predictions from literature. Some according trends obtained from experimental works are presented in the following paragraphs.

Figure 5(a) and (b) present the detail of the delamination damage between plies for both stacking sequences considered, the left column to simulations corresponding to using cohesive interaction and the right column to those based on Hou damage mode. The scale of the figure (common for both columns in order to allow comparison) ranges from 0 to 1 , the lower values corresponding to undamaged regions (light color) and the upper value with completely delaminated areas (dark color). Intermediate level of damage corresponds to the onset of delamination. It is remarkable the strong influence of damage mode (cohesive interaction or Hou model) on the predicted extension and level of delamination. Although equivalent parameters characterizing the onset and progression of delamination for both criteria were stated, Hou formulation undervalues delamination extension and level. Despite the lack of experimental tests focused on measurement of damage extension induced during orthogonal machining, it is possible to make some comparisons between numerical results obtained in this work and some works dealing with milling of composite. The work of Davim and Reis $^{25}$ analyzed the damage induced during milling of carbon composite showing delaminated areas between 1.007 and 1.154 times the mill diameter (up to $0.92 \mathrm{~mm}$ of penetration of delamination beneath the machined surface). Focusing on the test 1 reported by Davim and Reis, ${ }^{25}$ for the six-flute end mill, the lower value of cutting speed $(28 \mathrm{~m} / \mathrm{min})$ and feed rate $200 \mathrm{~mm} / \mathrm{min}$, a value of delamination factor equal to 1.083 is associated. Taking into account the value of the mill diameter equal to $6 \mathrm{~mm}$, the penetration of damage beneath the machined surface (half of the difference between the diameter of the damaged area and the mill diameter) is $0.249 \mathrm{~mm}$; approximately double of the feed in each revolution $(0.13 \mathrm{~mm} / \mathrm{rev}$ calculated from the data of cutting speed and feed rate).

Although it is not directly comparable, under a qualitative point of view, modeling of delamination with cohesive interactions in present work also gives a significant extension of damage greater than the feed in the most unfavorable cases (see Figure 5(a) and (b)).
Significant occurrence of delamination is also reported in a recent work of Hintze et al. ${ }^{23}$ focusing on milling of carbon composite. Cohesive interactions seem to be more adequate for delamination prediction than $\mathrm{Hou}$ model. It is worth to note that both the extension and level of damage are also sensitive to transverse resistance of the laminate against delamination, thus it is not possible to compare directly numerical and experimental damage since the studies are not carried out on the same composite and just a qualitative interpretation has been done.

The influence of stacking sequence can be observed in Figure 5(a) and (b). The laminate architecture influences the damage (both out-of-plane and intralaminar) induced during machining. Discussion concerning inplane failure modes (matrix and fiber) and the influence of stacking sequence on these failure modes can be found in a previous work of the authors. ${ }^{9}$ The largest delaminated areas correspond to the interface $0 / 90^{\circ}$ and $0 / \pm 45^{\circ}$.

On the other hand, when the plies are located at the free surface they tend to develop larger damaged zones (matrix damage) than when they locate at inner zone of the laminate. ${ }^{9}$

It is remarkable that the stacking sequence of the laminate is carefully selected for high-responsibility applications in order to optimize the material response to service loads. For instance, a sequence with external plies located at $45^{\circ}$ is commonly selected for axial loading (direction $0^{\circ}$ ) of composite bolted joints (see for instance Reference [3]). Joining requires previous drilling of the hole and commonly the component also needs contour milling in order to achieve dimensional specifications. As an example: the combination of increased damage at the external ply with a large delaminated region in the case recommended for axial loading of the component (external plies located at $45^{\circ}$ combined with adjacent ply oriented at $0^{\circ}$ ) could affect negatively the performance of the component and would advise to revise the design procedure accounting also for the machining stage.

\section{Conclusions}

This work has focused on the prediction of machininginduced damage when cutting carbon LFRP composite. A 3D finite element model of orthogonal cutting has been developed, including the modeling of out-of-plane failure using both classical Hou criteria and cohesive interactions. Cohesive interactions are required for accurate prediction of delamination phenomena and have been previously used in works dealing with dynamic loading of composites. However, cohesive interactions have not been used for chip removal due 
to the lack of 3D modeling of composite LFRP machining. On the other hand, laminate architecture of multidirectional laminates is carefully established when designing structural components since it affects the mechanical behavior of the component. The influence of stacking sequence in machining-induced damage has been analyzed through comparison between two quasi-isotropic laminates ([45/-45/0/90]s and $[90 / 0 / 45 /-45] \mathrm{s})$. Main conclusions obtained in the present work are summarized in the following:

- Cohesive interactions implemented in the 3D model have shown important differences in the prediction of damaged area when compared with classical formulation. Hou approach undervalued levels and extension of delamination damage. A qualitative comparison with experimental results from the literature, showing significant levels of damage, has shown more realistic predictions in the case of implementing cohesive interactions.

- The strong influence of the staking sequence on delamination damage induced during machining was demonstrated. The largest delaminated areas were observed at the interface $0 / 90^{\circ}$ and $0 / \pm 45^{\circ}$. Laminate architectures with these interfaces should be avoided at the free surface where the plies tend to develop larger damaged zones.

It has been highlighted in the paper the importance of designing composite components not only under the point of view of loading during service life but also accounting for the required machining operations. It has been also remarked the importance of using cohesive interactions for modeling of delamination in orthogonal cutting, showing more realistic behavior than that achieved with Hou model.

Despite the elevated computational cost, the use of $3 \mathrm{D}$ approaches seems to be necessary to succeed in reproducing the complex phenomena involved during composite cutting, including out of-plane-failure. Once the influence of interface modeling and the stacking sequence has been illustrated, it would be recommendable to advance in the complexity of the problem simulating current industrial processes.

\section{Funding}

Financial support for this work has been provided by the Ministry of Science and Innovation of Spain under the pro jects DPI2011 25999 and TRA2010 19573.

\section{References}

1. Cong WL, Pei ZJ, Deines TW, et al. Rotary ultrasonic machining of CFRP using cold air as coolant: feasible regions. J Reinf Plast and Comp 2011; 30: 899906.
2. Stone R and Krishnamurthy K. A neural network thrust force controller to minimize delamination during drilling of graphite epoxy laminates. Int J Mach Tools Manuf 1996; 36: 9851003.

3. Santiuste C, Barbero E and Miguélez H. Computational analysis of temperature effect in composite bolted joints for aeronautical applications. J Reinf Plast and Comp 2011; 30: 311 .

4. Ramesh MV, Seetharamu KN, Ganesan N, et al. Analysis of machining of FRPs using FEM. Int $J$ Mach Tools Manuf 1998; 38: 15311549.

5. Mahdi $\mathrm{M}$ and Zhang L. A finite element model for the orthogonal cutting of fiber reinforced composite mater ials. J Mater Process Technol 2001; 113: 373377.

6. Iliescu D, Gehin D, Iordanoff I, et al. A discrete element method for the simulation of CFRP cutting. Compos Sci Technol 2010; 70: 7380.

7. Santiuste C, Soldani X and Miguélez H. Machining FEM model of long fiber composites for aeronautical compo nents. Compos Struct 2010; 92: 691698.

8. Soldani X, Santiuste C, Muñoz Sánchez A, et al. Influence of tool geometry and numerical parameters when modelling orthogonal cutting of LFRP composites. Compos: Part A: Appl Sci Manuf 2011; 42: 12051216.

9. Santiuste C, Miguélez H and Soldani X. Out of plane failure mechanisms in LFRP composite cutting. Compos Struct 2011; 93: 27062713.

10. Durão LMP, Gonçalves DJS, Tavares JMRS, et al. Drilling tool geometry evaluation for reinforced compos ite laminates. Compos Struct 2010; 92: 15451550.

11. Durão LMP, De Moura MFSF and Marques AT. Numerical prediction of delamination onset in carbon/ epoxy composites drilling. Eng Fract Mech 2008; 75: 27672778.

12. Durão LMP, De Moura MFSF and Marques AT. Numerical simulation of the drilling process on carbon/ epoxy composite laminates. Compos Part A: Appl Sci Manuf 2006; 37: 13251333.

13. Singh I, Bhatnagar N and Viswanath P. Drilling of uni directional glass fiber reinforced plastics: experimental and finite element study. Mater Des 2008; 29: 546553.

14. Hocheng $\mathrm{H}$ and Dharan $\mathrm{CKH}$. Delamination during dril ling in composite laminates. $J$ Eng Ind 1990; 112: 236239.

15. Upadhyay PC and Lyons JS. On the evaluation of critical thrust for delamination free drilling of composite lamin ates. J Reinf Plast and Comp 1999; 18: 12871303.

16. Girot F, López de Lacalle LN, Lamikiz A, et al. Machinability aspects of polymer matrix composites in machining composites materials. New York, NY: Wiley\& Sons, 2009.

17. Davim JP, Reis $P$ and Antonio CC. Drilling fiber rein forced plastics (FRP) manufactured by hand lay up influ ence of matrix (VIAPAL VUP 9731 and ATLAC 382 05). J Mater Process Technol 2004; 155 156: 18281833.

18. Abrao AM, Campus Rubio J, Faria PE, et al. The effect of cutting tool geometry on thrust force and delamination when drilling glass fibre reinforced plastic composite. Mater Des 2008; 29: 508513. 
19. Davim JP, Campos Rubio J and Abrao AM. A novel approach based on digital analysis to evaluate the delam ination factor after drilling composite laminates. Compos Sci Technol 2007; 67: 19391945.

20. Rubio JC, Abrao A, Faria P, et al. Effects of high speed in the drilling of glass fibre reinforced plastic: evolution of the delamination factor. Int J Mach Tools Manuf 2008; 48: 715720 .

21. Krishnaraj V, Prabukarthi A, Ramanathan A, et al. Optimization of machining parameters at high speed dril ling of carbon fiber reinforced plastic (CFRP) laminates. Compos Part B: Eng, Epub ahead of print 20 January 2012. doi: 10.1016/j.compositesb.2012.01.007.

22. Liu DF, Tang YJ and Cong WL. A review of mechanical drilling for composite laminates. Compos Struct 2012; 94: 12651279.

23. Hintze W, Hartman D and Schütte C. Occurrence and propagation of delamination during the machining of carbon fibre reinforced plastics (CFRPs) an experimen tal study. Compos Sci Technol 2011; 71: 17191726.

24. Lopez de Lacalle N, Lamikiz A, Campa FJ, et al. Design and test of a multitooth tool for CFRP milling. J Compos Mater 2009; 43: 32753290.

25. Davim JP and Reis P. Damage and dimensional precision on milling carbon fiber reinforced plastics using design experiments. J Mater Process Technol 2005; 160: 160167.

26. Davim JP, Reis P and Antonio CC. A study on milling of glass fiber reinforced plastics manufactured by hand lay up using statistical analysis (ANOVA). Compos Struct 2004; 64: 493500.

27. Karpat Y, Bahtiyar O and Deger B. Mechanistic force modeling for milling of unidirectional carbon fiber rein forced polymer laminates. Int J Mach Tools Manuf 2012; 56: 7993.

28. Zaera R. Ballistic impacts on polymer matrix composites, composite armor, personal armor in impact engineering of composite structures. In: Abrate S (ed.) Impact engin eering of composite structures. New York, NY: Springer Vienna, 2011.
29. Wisnom MR. Modelling discrete failures in composites with interface elements. Compos: Part A: Appl Sci Manuf 2010; 41: 795805.

30. Aymerich F, Dore F and Priolo P. Prediction of impact induced delamination in cross ply composite laminates using cohesive interface elements. Compos Sci Technol 2008; 68: 23832390.

31. Dandekar CR and Shin YC. Modeling of machining of composite materials: a review. Int J Mach Tools Manuf, Epub ahead of print 2 February 2012. doi: 10.1016/ j.ijmachtools.2012.01.006.

32. Karlson $\mathrm{H}$ and Sorensen Inc. ABAQUS user's manual $6.41,2003$.

33. Iliescu D. Approache experimentale et numerique de l'usinage a sec des composites CARBONE/EPOXY. PhD Thesis, Ecole Nationale Supérieure des Arts et Métiers (ENSAM), Arts et Métiers ParisTech, CER de Bordeaux, France, 2008.

34. Hou JP, Petrinic N, Ruiz C, et al. Prediction of impact damage in composite plates. Compos Sci Technol 2000; 60: 228273 .

35. Chang FK and Chang KY. A progressive damage model for laminated composites containing stress concentra tions. J Compos Mater 1987; 21: 834855.

36. Olmedo Á and Santiuste C. On the prediction of bolted single lap composite joints. Compos Struct, Epub ahead of print 2 February 2012. DOI: 10.1016/ j.compstruct.2012.01.016.

37. Benzeggagh ML and Kenane M. Measurement of mixed mode delamination fracture toughness of unidirectional glass/epoxy composites with mixed mode bending appar atus. Compos Sci Technol 1996; 56: 439449.

38. Pernas Sánchez J, Artero Guerrero JA, Varas D, et al. In: Numerical modeling of high velocity impacts on carbon/epoxy woven laminates. (ed New design concepts in light weight armour for vehicles LWAG | light weight armour for defence and Security, Aveiro, Portugal, 2728 October 2011. 